\title{
Measurement of the changes of carbonaceous materials caused by intercalation of sodium deposited from molten salts electrolyte
}

\author{
Vladimír Danielik ${ }^{\mathrm{a}}$, Pavel Fellner ${ }^{\mathrm{a}}$, Marián Bobok ${ }^{\mathrm{a}}$, Jomar Thonstad ${ }^{\mathrm{b}}$ \\ ${ }^{a}$ Slovak University of Technology in Bratislava, Institute of Inorganic Chemistry, Technology and Materials, \\ Radlinského 9, SK - 81237 Bratislava, Slovakia \\ ${ }^{b}$ Norwegian University of Science and Technology, Department of Materials Science and Engineering, \\ N - 7491 Trondheim, Norway \\ vladimir.danielik@stuba.sk
}

\begin{abstract}
Intercalation of sodium into the carbon lining of aluminium electrolysis cells is a common cause of its failure. The effect of sodium on model carbon cathode materials was studied in the system with high activity of sodium (molten $\mathrm{NaF}-\mathrm{NaCl}$ system). Commercially available carbon materials such as semigraphite and electrographite (Kompozitum, Topolčany, SK) were chosen as model cathodes. The experiments were carried out at a constant cathode current density of $0.7 \mathrm{~A} \mathrm{~cm}^{-2}$. A modified Rapoport test was developed and used to study the expansion of the chosen types of carbon materials.
\end{abstract}

Keywords: intercalation into graphite, sodium intercalation, fluoride melts, Rapoport test, graphite swelling

\section{Introduction}

The carbon cathode is often referred to as the most important part of the aluminium electrolysis cell, because it is mostly that component that determines the life expectancy of the cell (along with the choice of materials, the quality of work, the start-up procedure and cell operation). Since shutdown, delining and relining operations of a cell represent important material and operating expenses, aluminium producers are increasingly anxious to achieve long service lives. Considerations of this kind are at the origin of the improvements in the production of carbon blocks and in cell operating parameters that enable today's cell to have a potential service life of about 3000 days. However, since many thermal, chemical and mechanical degradation processes may occur, many cells do not reach this goal (particularly when high current densities are applied). Furthermore, with increasing age, the cells usually become less efficient, the cathode voltage drop increases and the energy cost increases accordingly (Sørlie and Øye, 2010).

The consequence of sodium penetration in the carbon lining of aluminium electrolysis cells is an important cause of cell failure. This is the reason why this phenomenon has been studied extensively. When contemplating to move to more acid, low-melting baths in order to accommodate inert anodes, it is thus worthwhile to consider the consequences of such a change regarding sodium intercalation.

The monograph by Sørlie and Øye (2010) can serve as a comprehensive introduction to the subject.
However, intercalation of carbon (and graphite) is not of interest just from the point of view of aluminium electrolysis, but also for other applications of carbon and graphite, such as for instance lithium ion batteries. A comprehensive review of this topic has been published by Dresselhaus and Dresselhaus (2002). This review, which appeared in "Advances in Physics" in 2002, was first published in 1980, and since then it has been cited more than 450 times. Since that time, also other reviews on this subject have appeared.

There exist a series of books on "Chemistry and Physics of Carbon" published by Marcel Dekker Inc., New York and Basel. In Volume 20 in this series (Marsh et al., 1987), published in 1987, there is an interesting article on Intercalation.

In 2005, Brisson et al. (2005) published a review surveying almost 100 papers. In the same year a similar review appeared in the journal Acta Metallurgica Slovaca (Imriš et al., 2005), surveying ca 50 papers. In 2013, Chauke and Garbers-Craig (2013) published a paper on "Reactivity between carbon cathode materials and electrolyte based on industrial and laboratory data". They summarized theories on the formation of carbides, nitrides and cyanides in industrial cathode blocks along with some new laboratory and industrial experimental data. There are tens of other papers on this topic. All authors agree that intercalation of sodium into carbon cathode blocks occurs predominantly during cell start-up and the initial operation. After that the changes in cathode block properties are much slower.

An important characteristic of carbonaceous materials is their swelling when sodium intercalates into 
the material. Classical test for the determination of this property is the Rapoport - Samoilenko test (Rapoport and Samoilenko, 1957; Zolochevsky et al., 2003). In this paper we will describe a modified sensitive test and its application.

\section{Experimental}

In this work, we use three kinds of carbonaceous materials supplied by the company Kompozitum, a.s., Topol'čany, Slovak Republic. Semigraphite KU 121, KU 121G, and electrographite GU 111. The properties of these materials can be found on the web page www.kompozitum.sk. The material marked as KU $121 \mathrm{G}$ is the material KU 121, which was heated for $3 \mathrm{~h}$ in vacuum at $1500{ }^{\circ} \mathrm{C}$.

The electrolyte for sodium deposition was prepared from chemical purity "pro analysis". Prior to use, the chemicals were heated for $3 \mathrm{~h}$ at $600{ }^{\circ} \mathrm{C}$. Aluminium fluoride was prepared by sublimation of technical $\mathrm{AlF}_{3}$ in a platinum crucible (Danielik et al., 2012).

The Rapoport test is described in Rapoport and Samoilenko (1957). Some modifications are described in the monograph by Sørlie and $\emptyset$ ye (2010) and in papers by Zolochevsky et al. (2003), Zolochevsky et al. (2005). In this work we used the experimental arrangement depicted in Fig. 1a, b. In the original Rapoport and Samoilenko (1957) paper, the mixture $\mathrm{NaF}+\mathrm{AlF}_{3}$ having molar ratio $n(\mathrm{NaF}) / n\left(\mathrm{AlF}_{3}\right)=3$ was used as the electrolyte at the temperature $970{ }^{\circ} \mathrm{C}$. (The ratio $n(\mathrm{NaF}) / n\left(\mathrm{AlF}_{3}\right)$ is called the cryolite ratio. In modern aluminium smelters this ratio is lower than 2.7. High ratio supports sodium deposition.) Later the conditions for Rapoport test were standardized in ISO
15379-2:2004 in order to compare different carbon materials (temperature of electrolysis $980{ }^{\circ} \mathrm{C}$, electrolysis time $2 \mathrm{~h}$, sample diameter $30 \mathrm{~mm}$, cathodic current density $0.7 \mathrm{~A} \mathrm{~cm}^{-2}$, electrolyte composition $\mathrm{CR}=4.0$ containing $5.0 \% \mathrm{CaF}_{2}$ and $9.0 \% \mathrm{Al}_{2} \mathrm{O}_{3}$ ) (Sørlie and Øye, 2010).

In this work (Fig. 1) we used graphite crucible having inner diameter $40 \mathrm{~mm}$ and height $75 \mathrm{~mm}$. On the bottom of the crucible we placed a disc made of hot pressed boron nitride $(\mathrm{BN})$. The crucible was filled with pre-melted melt. In our tests we used also the eutectic mixture $\mathrm{NaF}-\mathrm{NaCl}$, which allows us to deposit pure metallic sodium at a temperature as low as $800^{\circ} \mathrm{C}$. (In aluminium electrolysis, temperature is close to $980{ }^{\circ} \mathrm{C}$ a thus the Rapoport test is carried out at this temperature.) The temperature was measured with a PtRh10 - Pt thermocouple. An inert argon atmosphere was maintained in the furnace, and the temperature was kept constant during the experiment. The test sample was a cylinder having diameter $6 \mathrm{~mm}$ and height $30 \mathrm{~mm}$. The conductive connection to the sample, which served as a cathode and to the graphite crucible, which served as the anode, was made of a steel $\operatorname{rod}(\varnothing=2.5 \mathrm{~mm})$ covered with copper. The conductor was screwed into the graphite crucible and the carbonaceous sample. A BN ring was placed on top of the sample. The conductive rods were protected also by corundum tubes. The whole sample was immersed in the melt, and the level of the melt reached up to the $\mathrm{BN}$ ring. A mark was made on the corundum tube sticking out from the furnace. Its position was measured with a cathetometer with the precision of $\pm 0.002 \mathrm{~mm}$. When the DC current was applied (the sample served as the cathode) sodium was deposited on the surface of the test sample. Sodium

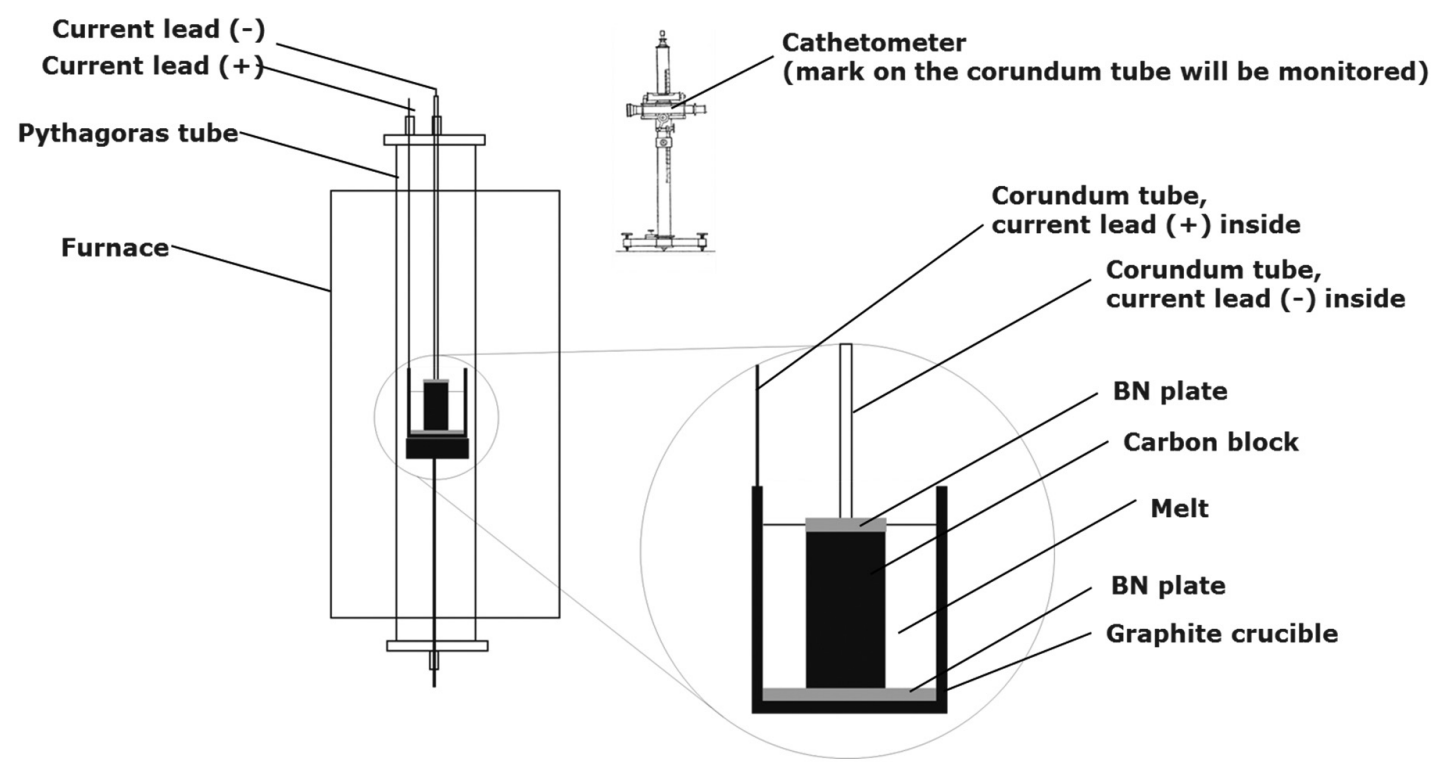

Fig. 1. Scheme of used apparatus. 
penetrated into the sample due to intercalation, and the dimensions of the sample changed.

\section{Results and Discussion}

\section{Modified Rapoport test carried out in the eutectic} melt of the system $\mathrm{NaF}-\mathrm{NaCl}$.

As mentioned above, pure metallic sodium can be deposited from this melt. The temperature of the eutectic mixture is $688^{\circ} \mathrm{C}$. The boiling temperature of sodium at atmospheric pressure is $882.94{ }^{\circ} \mathrm{C}$. In
Figs. 2-4 the results of the experiment carried out at three different temperatures with the cathodic current density of $0.7 \mathrm{~A} \mathrm{~cm}^{-2}$ for three different materials are presented. The reproducibility of the experiments was $0.03 \%$ (for 3 parallel experiments).

The expansion is related to the original length of the cylinder, serving as cathode. It can be seen that a time of $120 \mathrm{~min}$ was in most case sufficient for reaching steady conditions. Maximum change (swelling) appeared in the first minutes after start-

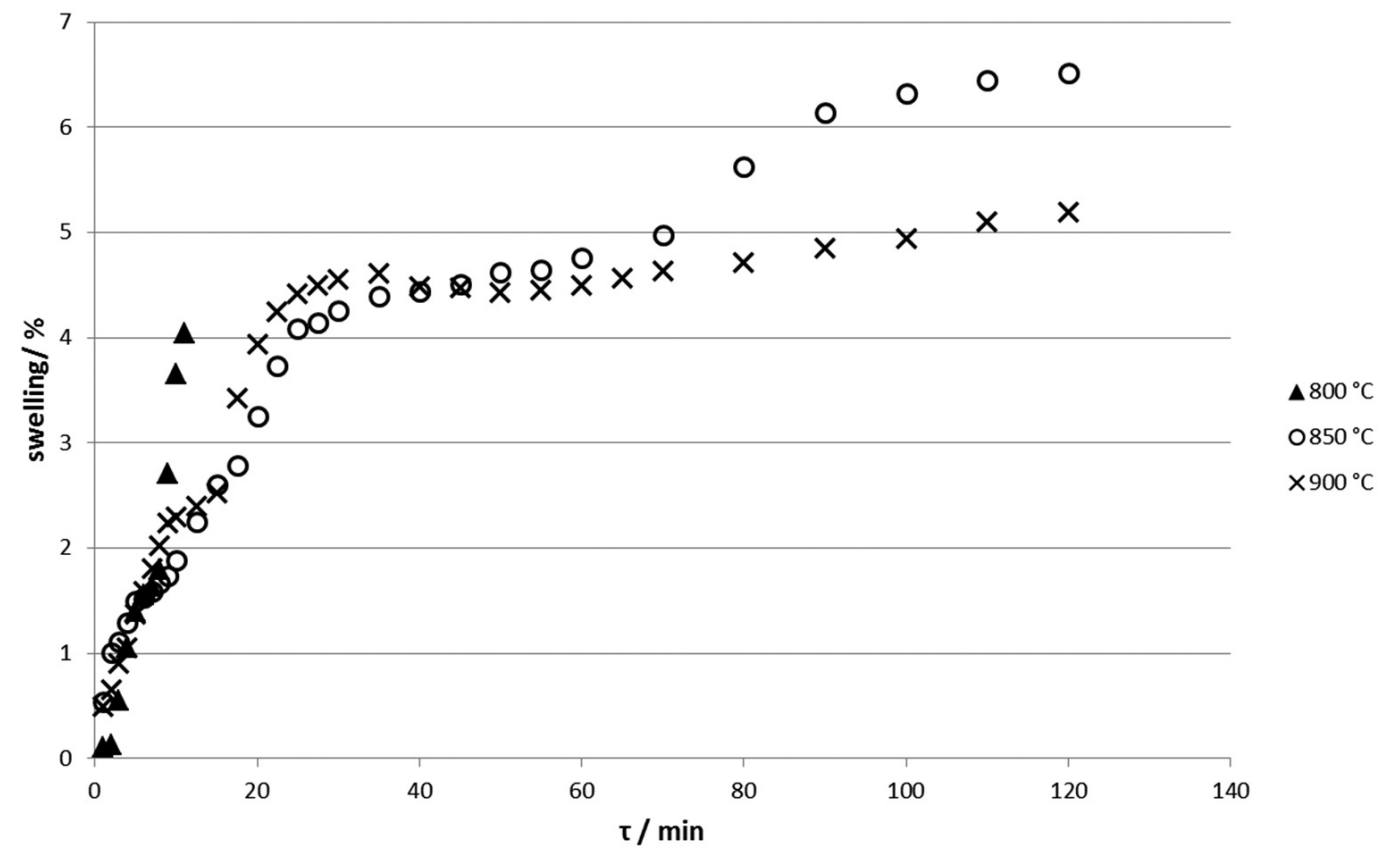

Fig. 2. Time depencence of the dimensional changes of the sample KU 121 in the eutectic mixture $\mathrm{NaF}-\mathrm{NaCl}$.

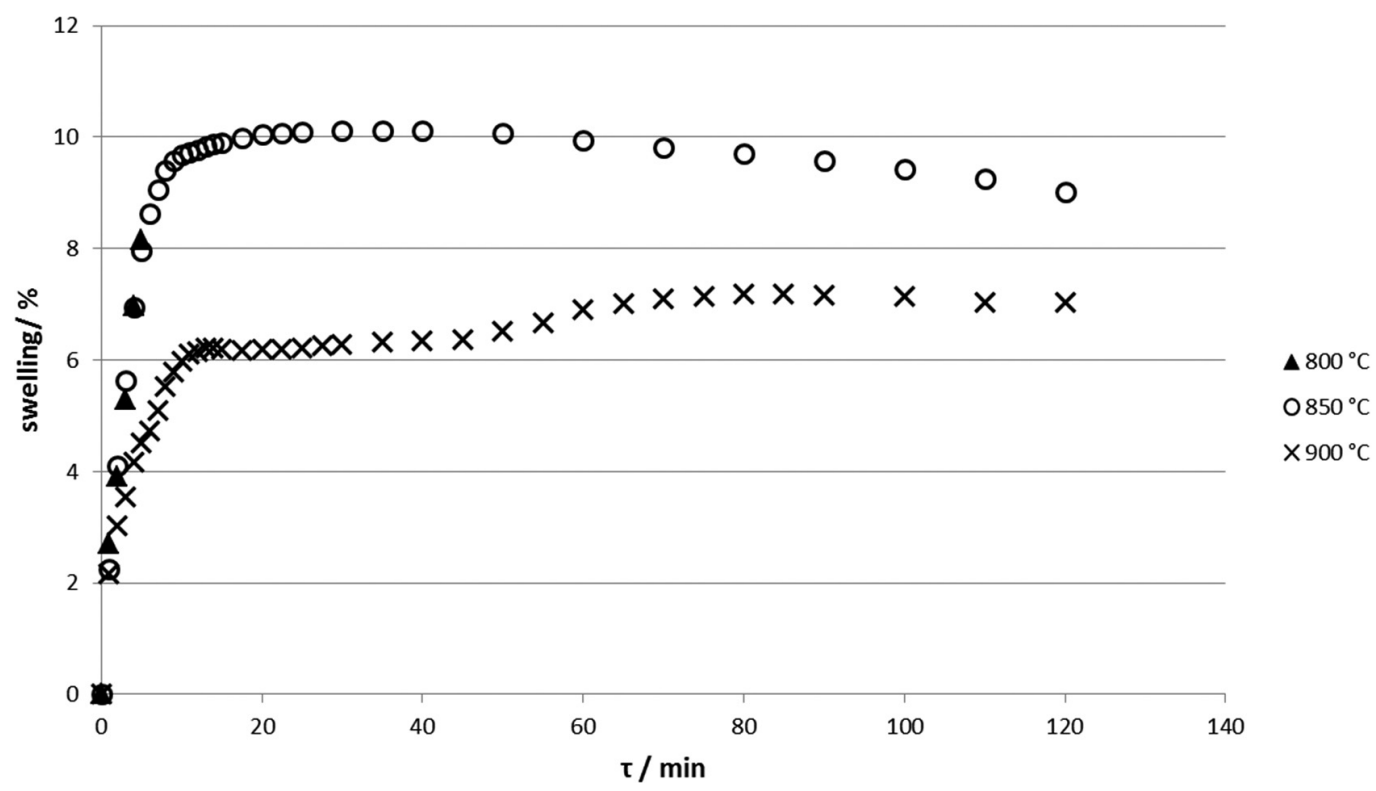

Fig. 3. Time depencence of the dimensional changes of the sample KU $121 \mathrm{G}$ in the eutectic mixture $\mathrm{NaF}-\mathrm{NaCl}$. 


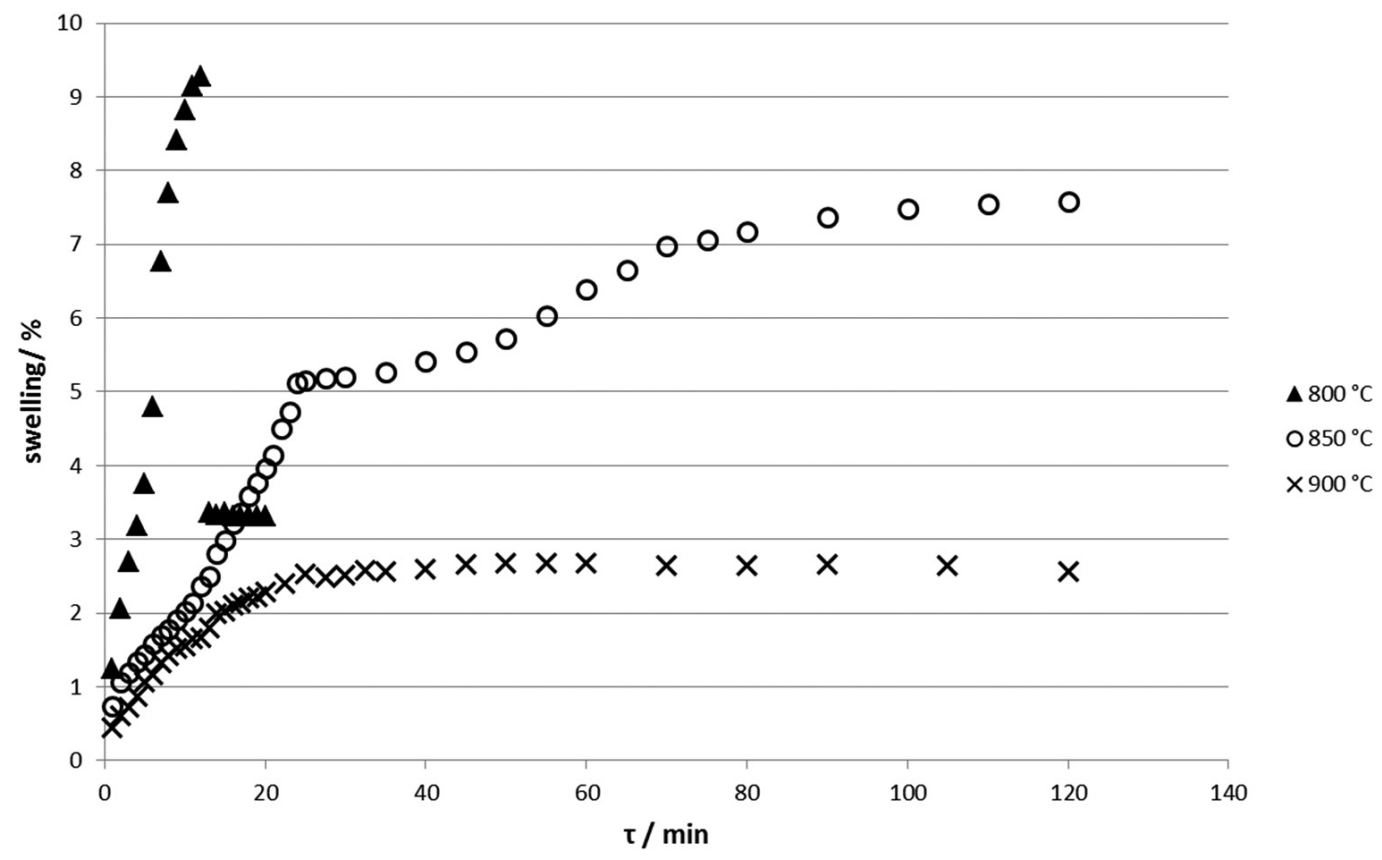

Fig. 4. Time depencence of the dimensional changes of the sample GU 111 in the eutectic mixture $\mathrm{NaF}-\mathrm{NaCl}$.

ing the deposition of sodium onto the surface of the test sample.

The lower was the temperature, the higher was the swelling. This is in agreements with Naas (1997), Borisenko et al. (2003) and Zhang et al. (2012). This behaviour can be explained by the fact that the compounds of carbon and sodium are more stable at lower temperatures. In all cases (Figs. 2-4) the expansion at $800{ }^{\circ} \mathrm{C}$ was so big (> $10 \%$ ) that the sample decomposed. According to Dresselhaus and Dresselhaus (2002), the entropy of formation of the compounds formed by carbon and alkali metals $\mathrm{C}_{\mathrm{x}} \mathrm{M}(\mathrm{x}=8-60, \mathrm{M}=\mathrm{K}, \mathrm{Rb}, \mathrm{Cs})$ is about $-85 \mathrm{~J} \mathrm{~K}^{-1} \mathrm{~mol}^{-1}$. The enthalpy and Gibbs energy of formation of these compounds is also negative $\left(\Delta_{f} H^{0}=-117000 \mathrm{~J} \mathrm{~mol}^{-1}\right)$. It follows that with increasing temperature the Gibbs energy becomes positive. If we assume that sodium intercalation compounds with carbon behave in a similar way, we can explain why intercalation of sodium increases with decreasing temperature.

\section{Acknowledgement}

This work was supported by courtesy of the Slovak Grant Agency (VEGA 1/0101/14).

\section{References}

Borisenko N, Sytchev J, Kaptay G (2003), Journal of Mining and Metallurgy 39B(1-2): 269-381.

Brisson PY, Soucy G, Fafard M, Dionne M (2005), Canadian Metallurgical Quarterly, 44(2): 265-280.

Chauke L and Garbers-Craig AM (2013), Carbon 58: 40-45.

Danielik V, Fellner P, Suleková D, Thonstad J (2012), J. Electrochem. Soc. 159(2): C86-C89.

Dresselhaus MS, Dresselhaus G (2002) Advances in Physics 51(1): 1-186.

Imriš M, Soucy G, Fafard M (2005), Acta Metallurgica Slovaca 11(2): 231-243.

Marsh H, Murdie N, Edwards IAS, Boehm HP (1987), Chemistry and Physics of Carbon, Vol. 20. CRC Press.

Naas T (1997), Thesis. NTNU Trondheim, Norway.

Rapoport MB, Samoilenko VN (1957), Tsvetnye Metalli 30(2): 44-51.

Sørlie M, Øye HA (2010) Cathodes in Aluminium Electrolysis, $3^{\text {rd }}$ Edition. Aluminium-Verlag GMBH, Düsseldorf.

Zhang Y, Feng N, Peng J, Wang Y, Han Y, Zhai X (2012), Light Metals 2012: 681-684.

Zolochevsky A, Hop JG, Servant G, Foosnaes T, Øye HA (2003), Carbon 41(3): 497-505.

Zolochersky A, Hop JG, Foosnaes T, Øye HA (2005), Carbon 43(6): 1222-1230. 